\title{
VIVÊNCIAS DE UMA EQUIPE DE ENFERMAGEM NO CUIDADO A PACIENTES COM CÂNCER*
}

\author{
Eniva Miladi Fernandes Stumm¹ ${ }^{1}$ Marinês Tambara Leite², Gislaine Maschio³
}

\begin{abstract}
RESUMO: O termo câncer designa um conjunto de doenças cuja incidência tem sido progressiva nos últimos anos. O estudo busca conhecer vivências da equipe de enfermagem de uma unidade oncológica relacionadas ao cuidado a pacientes com câncer. Pesquisa qualitativa, descritiva, exploratória, desenvolvida em um Hospital do Rio Grande do Sul. Participaram os sete profissionais de enfermagem que atuam na unidade de oncologia. Na coleta de dados utilizou-se entrevista aberta, com a questão norteadora: fale-me como é para você cuidar de pacientes com câncer? Também foi realizada observação participante. Para a análise das informações seguiu-se os passos preconizados para análise temática, resultando na estruturação da categoria analítica denominada: a enfermagem cuidando e convivendo com o paciente oncológico. O cuidado ao paciente oncológico ocorre de forma interacional, havendo troca mútua de idéias, emoções e sentimentos. Para os profissionais a ação de cuidar requer compreensão, atendimento humanizado e formação de vínculo entre equipe, pacientes e familiares.
\end{abstract}

PALAVRAS-CHAVE: Enfermagem; Cuidados de enfermagem; Oncologia.

\section{A NURSING TEAM’S EXPERIENCES RENDERING CARE TO CANCER PATIENTS}

ABSTRACT: The term cancer entails a set of diseases that have been having a progressive incidence in the last few years. This study intends to know a nursing team's experiences in an oncological unit, rendering care to cancer patients. It is a qualitative, descriptive and exploratory research, developed in a Hospital in Rio Grande do Sul State, Brazil. Seven nursing professionals from the oncological unit participated in the study. Data collection was performed through an open interview, guided by the question: "tell me how it is to take care of cancer patients". Participant observation was also carried out. Information analysis followed the steps recommended for thematic analysis, resulting in the construction of an analysis category, which we called: nursing delivering care and living with oncological patients. Care delivery to oncological patients occurs in an interactional way, in which there are mutual ideas, emotions and feelings' exchange. For the professionals, caring action requires understanding, humanized care delivery and bonding among team, patients and family members.

KEYWORDS: Nursing; Nursing care; Oncology.

\section{VIVENCIAS DE UN EQUIPO DE ENFERMERÍA EN EL CUIDADO A PACIENTES CON CÁNCER}

RESUMEN: El termino “cáncer” designa un conjunto de enfermedades en que la incidência viene siendo progresiva en los últimos años. El estudio busca conocer las vivencias del equipo de enfermeria de una unidad oncológica relativas a la asistencia a pacientes con cáncer. Investigación cualitativa, descriptiva, exploratoria, desarrollada en un hospital del Estado de Rio Grande do Sul - Brasil. Participaron todos los siete profesionales de enfermería que actúan en la unidad de oncología. En la recolección de datos, se utilizó la encuesta abierta con la cuestión orientadora: "Hableme como es para usted cuidar de pacientes con câncer.”. También fue realizada la observación participante. El análisis de las informaciones seguió los pasos preconizados para na'slisis temático, lo que resultó en la estructuración de una categoría analítica llamada de: enfermería cuidando y conviviendo con el paciente oncológico. El cuidado al paciente oncológico ocurre de forma interaccionad, habiendo cambio mutuo de ideas, emociones y sentimientos. Para los profesionales, la acción de cuidar requiere comprensión, atención humanada y formación de vínculo entre equipo, paciente y familiares.

PALABRAS CLAVE: Enfermería; Atención de enfermería; Oncología.

\footnotetext{
*Artigo produzido a partir do Trabalho Monográfico de conclusão do Curso de Enfermagem da Universidade Regional do Noroeste do Estado do Rio Grande do Sul - Unijuí.

${ }^{1}$ Enfermeira. Mestre. Docente do Departamento de Ciências da Saúde da Unijuí.

${ }^{2}$ Enfermeira. Doutora em Gerontologia Biomédica. Docente do Departamento de Ciências da Saúde da Unijuí.

${ }^{3}$ Enfermeira. Egressa do Curso de Enfermagem da Unijuí.
}

Autor correspondente:

Eniva Miladi Fernandes Stumm

Rua 20 de setembro, 902 - 98700-000 - Ijuí-SC

Recebido: 31/01/08

E-mail: eniva@unijui.edu.br

Aprovado: 19/05/08 


\section{INTRODUÇÃO}

A inserção da equipe de enfermagem no cuidado ao paciente oncológico requer conhecimentos, habilidades e responsabilidades. Nesse sentido, as metas devem ser claras e direcionadas ao paciente, sua família e demais pessoas significativas, contemplando os aspectos físico, emocional, social e espiritual.

O câncer ainda é entendido pelas pessoas, em geral, como sinônimo de dor, morte e sofrimento. Nesta perspectiva, cabe a enfermagem identificar suas próprias concepções relativas ao câncer e estabelecer estratégias de enfrentamento, visando uma assistência adequada e eficaz que possibilite minimizar o sofrimento de todos os envolvidos no processo de cuidar.

Frente a um diagnóstico de câncer, cada ser responde de modo individual, porém reações como medo, ansiedade, negação, desesperança e perda de controle são comuns. Neste cenário, a equipe de saúde, em especial, a de enfermagem é a que está mais próxima e por um período maior, do paciente e seus familiares, portanto, apta a prestar atendimento humanizado, compreendendo-os e apoiando-os em todas suas necessidades, no decorrer do processo do adoecimento. A assistência de enfermagem exige presença, flexibilidade, co-responsabilidade, partilha de sentimentos, conhecimentos e solidariedade ${ }^{(1)}$.

$\mathrm{O}$ aumento progressivo dos diversos tipos de câncer tem levado pesquisadores a estudar e buscar desvendar a etiologia, bem como as modalidades de tratamento. Segundo o Instituto Nacional do Câncer (INCA) $^{(2)}$, a etiologia do câncer é multicausal e resulta da interação de vários fatores de risco, favorecendo em maior ou menor extensão a probabilidade do indivíduo ter a doença. A divisão das células cancerosas ocorre de forma rápida, tende a ser agressiva e incontrolável, formando aglomerações tumorais ou neoplasias malignas. Assim, podem surgir mutações a partir da ativação anormal de genes celulares controladores do crescimento e das mitoses celulares.

O diagnóstico de câncer se dá a partir do estádio e do grau em que o tumor se encontra. A identificação da doença é realizada em etapa anterior ao início do tratamento, visando à obtenção de parâmetros de avaliação e à proposição da modalidade de intervenção mais adequada ${ }^{(3)}$. Dessa forma, o diagnóstico baseiase na análise das alterações fisiológicas e funcionais e nos resultados da investigação realizada.

Cuidar de pessoas com câncer é trabalhar com vida, não importando o tempo de que a mesma dispõe e, portanto, considera-se que estas pessoas são merecedoras de assistência integral. O cuidado integra o papel da equipe de enfermagem, possibilitando o movimento de ações pela manutenção da vida. Cuidar do ser humano constitui-se a essência do trabalho em enfermagem ${ }^{(4)}$.

Para que as ações de enfermagem no cuidado ao paciente oncológico sejam integrais, participativas e resolutivas, os profissionais, em todos os níveis de atuação, devem possuir conhecimentos técnicocientíficos e habilidades no relacionamento interpessoal, favorecendo ações de saúde e práticas educativas, no sentido de prevenir, detectar precocemente o câncer e contribuir no tratamento do mesmo.

Considerando que o cuidar é uma ação fundamental para a promoção e recuperação da saúde, a atuação da equipe de enfermagem torna-se essencial, especialmente com o paciente oncológico, inclusive quando não há perspectivas de cura e nem de sobrevida ${ }^{(5)}$.

A partir destas considerações, esta pesquisa busca responder a seguinte indagação: como é para a equipe de enfermagem, que atua em uma unidade oncológica, cuidar de pacientes com câncer? Com o objetivo de compreender as vivências da equipe de enfermagem de uma Unidade Oncológica, relacionadas ao cuidado de pacientes com câncer.

\section{PERCURSO METODOLÓGICO}

Este estudo caracteriza-se como uma pesquisa de abordagem qualitativa, descritiva e exploratória, desenvolvida em uma unidade oncológica de um hospital da Região Norte do Estado do Rio Grande do Sul. Os sujeitos foram os sete trabalhadores que integram a equipe de enfermagem que atua na referida unidade sendo que dois são enfermeiros e cinco são técnicos em enfermagem; todos do sexo feminino; cinco casadas e três solteiras e a idade variou de 24 a 51 anos.

Para a coleta das informações foi utilizada entrevista aberta, gravada em áudio tape, com a seguinte questão norteadora: fale-me como é para você cuidar de pacientes com câncer? Esta questão foi complementada com observação participante, utilizando-se um roteiro e as informações registradas em diário de campo. Os dados coletados foram analisados conforme proposta metodológica de Minayo ${ }^{(6)}$, a qual compreende: ordenação, classificação dos dados e análise final, seguindo, ainda, os passos preconizados para análise temática. Os resultados 
estão apresentados de modo descritivo, os quais possibilitaram a construção de uma categoria analítica, assim denominada: a enfermagem cuidando $e$ convivendo com o paciente oncológico.

Os aspectos éticos foram observados conforme prevê a Resolução 196/96 do Conselho Nacional de Saúde ${ }^{(7)}$. O projeto foi aprovado para sua execução, mediante parecer consubstanciado $n^{\circ}$. 56/2006 do Comitê de Ética em Pesquisa da Universidade Regional do Noroeste do Estado do Rio Grande do Sul.

Para garantir o anonimato dos sujeitos, os mesmos foram identificados pelos autores com codinomes de caranguejos existentes no Brasil: Guaiamu, Aratu, Azul, Eremita, Uçá, Real e Vermelho. Essa escolha ocorreu pelo fato de a palavra câncer ter origem no latim "cancri”, que significa caranguejo e usado como símbolo de tal patologia, sendo suas patas comparadas à característica infiltrativa do câncer.

\section{RESULTADOS}

A partir da análise das informações elaboramos uma categoria temática - a enfermagem cuidando e convivendo com o paciente oncológico - para a qual convergiu o conteúdo expresso nas falas dos sujeitos. Esta categoria faz referência ao papel da equipe de enfermagem frente à necessidade de cuidado do paciente oncológico, nas diferentes etapas que integram o diagnóstico, o tratamento e a reabilitação. Além disso, apontam que os profissionais de enfermagem devem estar adequadamente qualificados para proporcionar um cuidado efetivo e afetivo, simultaneamente.

Compete à equipe de enfermagem oncológica, além das atribuições de cunho técnico e assistencial, atividades de caráter educativo, relativas à prevenção, detecção precoce, cuidados e reabilitação, envolvendo equipe, pacientes e familiares. Essas ações, uma vez concretizadas, contribuem na melhoria da qualidade de vida ou sobrevida dos pacientes oncológicos.

A atuação do enfermeiro na reabilitação e tratamento do paciente com câncer é ampla e variada as suas intervenções. O planejamento é realizado considerando as especificidades vivenciadas de cada paciente. O processo de reabilitação tem como alvo o paciente e a família, requerendo que a assistência seja prestada de forma holística ${ }^{(8)}$.

O depoimento de Guaiamu evidencia as habilidades e conhecimentos da equipe, necessárias ao cuidado de pacientes e familiares:
Cuidar de pacientes com câncer exige realmente muita dedicação, paciência, compreensão da família, do paciente, saber que de repente [...] logo após o diagnóstico da doença, ele vem, grita, agride [...] ele ou a família, saber trabalhar isso. De repente não é a nós que ele está agredindo, mas ele está vivendo uma situação que o momento faz com que ele se revolte com a primeira pessoa que aparecer na frente (Guaimu).

Nesta fala emerge a preocupação em cuidar do paciente em todas as etapas do processo de adoecimento, seja ela de revolta, agressão ou mesmo de satisfação. A equipe de enfermagem reconhece o paciente oncológico em situação de fragilidade e insegurança, devendo estar preparada para cuidar, tendo por base o conhecimento técnico-científico, estabilidade emocional e habilidade nas relações interpessoais. O profissional ao reconhecer e compreender as atitudes e reações dos pacientes favorece a aceitação e reduz o desgaste de ambos os agentes envolvidos no cuidado.

Cuidado é entendido como ir ao encontro, dar sentido às existências, buscar transpor a realidade do sofrimento e da dor, mediante formas criativas e efetivas e vislumbrando novos horizontes de cuidado. Desta maneira, o cuidar na enfermagem se traduz em uma dinâmica de troca e interação, alicerçada na confiança, respeito, ética e na experiência compartilhada de vida ${ }^{(9)}$.

No processo de cuidado interativo/intersubjetivo o profissional envolve-se com o outro, no sentido de permanecer junto e de entra-ajuda recíproca. Dessa forma, o cuidado ultrapassa a barreira do conhecimento científico, do simples ato simbólico ou procedimento técnico. Isto pode ser verificado na manifestação do que existe de mais humano naquele que é cuidado e naquele que cuida ${ }^{(10)}$.

$\mathrm{Na}$ manifestação de Azul destaca-se a importância que a equipe de enfermagem atribui à atualização técnico-científica e, também, a personalização no cuidado, incluindo reações frente ao diagnóstico e tratamento:

São inúmeras as medicações que surgem. Então tem que saber o que essa medicação faz, os cuidados para minimizar os efeitos colaterais, pois cada indivíduo é diferente e vai responder de modo individual ao tratamento e ao impacto do diagnóstico (Azul). 
Evidencia-se a preocupação da equipe quanto ao conhecimento dos medicamentos administrados nos pacientes: efeitos colaterais, conduta frente ao extravasamento e tempo de infusão dos quimioterápicos. Enfermeiros que cuidam de pacientes oncológicos trabalham num ambiente de grande exigência, seja pela alta complexidade dos tipos de câncer, seja pelas manifestações de cada indivíduo, requerendo do profissional constante atualização $0^{(11)}$.

Cuidar de pacientes com câncer, no relato de Guaimu, exige carinho e atenção especial, pois eles se encontram fragilizados com o diagnóstico de uma doença que carrega consigo um estigma nada promissor:

É uma especialidade que exige além do conhecimento técnico, carinho especial da equipe em relação às pessoas, porque eles têm necessidade. Às vezes, não envolve técnica nem atenção, mas carinho, um sorriso [...] (Guaiamu).

Os pacientes oncológicos carecem de afeto e o contato assíduo com a equipe de enfermagem propicia compartilhamento de sentimentos e emoções, podendo resultar em empatia. Essa proximidade é observada, geralmente, com pacientes em tratamento por longo período, mas atitudes dos profissionais que envolvem carinho, respeito e receptividade ocorrem independentes do tempo de tratamento. A equipe de enfermagem ao se envolver emocionalmente com o paciente, estabelece uma relação autêntica, vital na terapêutica, atendendo suas necessidades ${ }^{(12)}$.

$\mathrm{O}$ envolvimento favorece a empatia e essa se torna essencial quando se propõe a ajudar alguém. A palavra empatia é de origem grega-empatheia, significa tendência para sentir o que sentiria caso estivesse na situação e circunstância experimentadas, vivenciadas por outra pessoa. É uma habilidade que pode ser desenvolvida de forma verbal e não-verbal ${ }^{(13)}$. Na empatia é fundamental o respeito mútuo, o cuidado individualizado, valorização das crenças, cultura e valores de cada pessoa. Eremita manifesta que a empatia está presente no trabalho da equipe na unidade pesquisada:

Pode ser eu hoje, ou um familiar amanhã. Penso que é importante conversar com o paciente, dar atenção, porque pode ser um familiar meu, para ele também vai ser importante ter alguém que o trate de forma humanizada (Eremita).

Ao colocar-se no lugar do outro, o profissional toma consciência de que sente e é capaz de avaliar e escolher como gostaria de ser cuidado. O cuidador ao colocar-se no lugar do ser cuidado, entende suas dificuldades e necessidades. A equipe de enfermagem dispõe de empatia para comunicar-se com os pacientes e nela inclui a capacidade de sentir o mundo e os acontecimentos $^{(14)}$. Ações empáticas proporcionam forças, energiza o outro, sem provocar desgaste no cuidador $^{(10)}$. Agir com empatia significa, também, entristecer-se e, por vezes, chorar com o paciente.

Eu gosto de cuidar desses pacientes, do contato, de conversar. Tem que ver sob outro ângulo, da dor [...] eles são pacientes especiais, dou afeto, fico atento à parte psicológica. Eles conversam bastante, questionam, a gente esclarece quanto ao tratamento, pergunto como eles estão, como está o tratamento, se estão se alimentando, se tem lesão na área do tratamento e eles contam tudo[...] (Vermelho).

Aqui na quimioterapia temos contato direto com o paciente, podemos sentir mais eles, trocar idéias. Eles falam das experiências, dos medos, das angústias [...] essa troca de convivências é muito boa [...] a equipe procura trabalhar junto com os pacientes (Uçá).

Analisando o conteúdo dessas falas, pode-se afirmar que a comunicação é parte integrante do cuidado, um instrumento importante na prática de enfermagem, favorecendo a interação com os pacientes, ajudando-os a suprir suas necessidades, dúvidas e anseios. Ela contribui para um relacionamento efetivo, no qual o enfermeiro proporciona ao paciente apoio, conforto, informação e sentimentos de confiança e de autoestima. A comunicação entre equipe e pacientes está presente em todos os momentos do cuidado, incluindo a comunicação verbal e não-verbal.

Importante destacar que no cuidado prestado pela equipe de enfermagem, além da empatia, saber ouvir é fundamental. Escutar com atenção, entender as diferenças individuais, permitir que o outro escute, só assim poderá haver compreensão. Assim, reconhecese que se deve ver mais, escutar mais e falar menos ${ }^{(15)}$.Na fala de Real evidencia-se o quanto a equipe valoriza estes aspectos, incluso no ato de cuidar:

Eles contam tudo o que estão vivenciando em casa. Então tem que fazer as duas partes, administrar 
os cuidados, conversar e dar apoio. Deixá-los tranqüilos para poder voltar novamente, para que não desistam, eles têm que continuar o tratamento (Real).

No espaço da unidade de oncologia, o paciente carece de cuidados que atendam suas necessidades básicas de natureza orgânica, psicológica e, também, deve sentir-se respeitado e compreendido, com liberdade para expressar seus sentimentos. Daí a importância da equipe de enfermagem estar presente e disponível, tanto quanto possível, sendo pacienciosa, cuidadosa e apta a ouvir o que o paciente tem a dizer ${ }^{(16)}$. Aratu reconhece a necessidade que os pacientes possuem de compartilhar com a equipe suas vivências relacionadas à patologia e as dificuldades relativas ao tratamento. Admite, também, que necessitou adaptar-se à nova realidade:

Quando eu vim para cá eu esperava que tivesse mais técnicas de enfermagem, curativos... mas aqui a parte assistencial é mais forte. É muito bom conversar, dar atenção [...] é isso o que os pacientes mais precisam na realidade (Aratu).

A convivência entre equipe e pacientes favorece a formação de vínculos, que ultrapassam o âmbito profissional, revela uma relação verdadeira, por meio de interação, troca de conhecimentos, experiências e sentimentos. Isto é evidenciado no depoimento a seguir:

Procuro passar segurança, calma, tranqüilidade $e$ amizade. Aqui é uma família, o tratamento é longo, ficam meses, às vezes um ano conosco e a gente se apega e eles também. Na rua cumprimentam às vezes a gente não lembra quem é de tantos que são, mas é uma emoção grande quando encontramos esses pacientes na rua $e$ vemos que estão bem (Uçá).

O vínculo pode ser compreendido como a capacidade de escutar o ser humano na sua singularidade, estreitando a relação enfermeiro-paciente. É sentir no ser cuidado a importância de quem cuida. Nos depoimentos de Real e Eremita emerge a inclusão da família no cuidado ao paciente oncológico:

Às vezes o paciente vem sozinho, mas nós mantemos um elo com aquelas pessoas que estão lá fora cuidando desses pacientes, para poder orientar $e$ saber como ele é cuidado lá fora (Real).

A gente incentiva a família e o paciente para que procurem atendimento, não abandonem $o$ tratamento e tenham menos sintomas. Sempre damos atenção, carinho, uma palavra de afeto $e$ de conforto aos familiares (Eremita).

Analisando as manifestações de Eremita e Real, identifica-se que o cuidado de enfermagem não se restringe a assistência terapêutica ao paciente, mas também a seus familiares, cumprindo seu papel diante da situação vivenciada pelo paciente.

Ao incluir a família nos cuidados dispensados aos pacientes, a equipe informa sobre a doença, tratamento, efeitos colaterais dos medicamentos, dentre outros. Ela estimula o familiar para permanecer ao lado do paciente inclusive durante as sessões de quimioterapia.

Outro aspecto refere-se às orientações a pacientes que fazem uso de medicamentos via parenteral ou oral, sendo essas também fornecidas aos familiares. Muitas vezes, os pacientes não possuem condições de assimilar tais informações, uma vez que se encontram debilitados e precisam de ajuda do familiar para continuar o tratamento.

A conduta da equipe de enfermagem, relacionada aos pacientes e familiares, vai ao encontro do que afirmam em seus depoimentos, mostrando-se amável, receptiva, compreensiva e com conhecimento técnico-científico. No entanto, a equipe de enfermagem igualmente se depara em seu cotidiano, com inúmeras situações de sofrimento, o que a faz sofrer também e pode ser evidenciado na fala de Azul:

Tem casos, como de um paciente que estava fazendo quimioterapia e estava bem, super bem, agora está todo edemaciado, não caminha, totalmente diferente. Aí tu fica com aquele sentimento [...] ele estava indo tão bem e decaiu desse jeito (Azul).

Igualmente, no discurso de Eremita, emerge o fato do profissional de enfermagem levar para fora de seu ambiente de trabalho sentimentos e emoções em relação aos pacientes, embora se esforce para manterse centrada em sua tarefa de cuidar no ambiente hospitalar:

Às vezes a gente sai daqui e fica pensando naquele 
paciente que está sofrendo [...] pode ser que hoje ele esteja bem [...] amanhã pode ser que o tratamento não possa ser concluído. A gente fica pensando nesses pacientes (Eremita).

Uçá e Vermelho demonstram em suas falas o sentimento de impotência frente ao inevitável:

Tem um lado terrível, que é a morte. Alguns pacientes já vieram mal, internaram. Esse lado é bem ruim, é muito difícil dizer para um familiar o seu parente está "indo". Você se sente com as mãos presas porque não tem mais o que fazer (Uçá).

A gente fica naquela expectativa, será que o paciente vai melhorar, não vai [...] alguns, em fase mais avançada, provavelmente vão a óbito. A gente fica [...]. Ah! ele estava aqui ontem, hoje já não está mais, como pode?' A gente fica com esta pergunta (Vermelho).

Aratu deixa transparecer sua aflição frente o paciente sem perspectivas terapêuticas, deixando claro o medo de se envolver emocionalmente, pois precisa atender os demais, demonstrando o máximo de positividade:

Tem que ter força para não se abalar com as coisas. Tem um paciente ali hoje, que nem terminou as radioterapias... ele veio, me abraçou, me deu tchau, saiu chorando. Eu tentei alegrar ele, dar conforto, mas depois que ele saiu fiquei imaginando, coitado! Não posso deixar me abalar com isso e não cuidar dos outros, não posso entrar em depressão por causa de um paciente (Aratu).

Percebe-se que a equipe de enfermagem, para conviver com o sofrimento, cotidianamente, utiliza mecanismos de enfrentamento: distancia-se dos pacientes e evita envolver-se, o que denota o despreparo para lidar com a carga emocional resultante do convívio diário com pacientes oncológicos. A resistência da equipe de enfermagem no que se refere ao envolvimento com os pacientes se deve, geralmente, ao receio de sofrer pela perda e ainda confrontar-se com seus próprios sentimentos em relação à morte ${ }^{(17)}$.

A equipe pesquisada sofre ao presenciar a piora do quadro do paciente oncológico e se solidariza com ele, porém a grande dificuldade reside no permanente contato com a possibilidade da terminalidade da vida. No entanto, o cuidado a esses pacientes é similar àqueles prestados aos pacientes com perspectiva de cura, visando proporcionar condições dignas e melhor qualidade de vida possível.

O sofrimento da equipe emerge nos depoimentos obtidos, porém há também presença de sentimentos de satisfação em conviver e acompanhar os pacientes que obtêm êxito no tratamento ministrado, inclusive a cura. Esse sentimento é observado na fala de Uçá:

É muito gratificante, tem pacientes que conseguem vencer, terminando o tratamento, vem fazer a última sessão, e não vão mais voltar aqui. A gente só vai se ver na rua ou em algumas festas, esse lado é muito gratificante. É uma vitória enorme pra eles e para nós (Uçá).

O cuidado de enfermagem é efetivo, eficaz e satisfatório no momento em que alivia a dor, conforta o paciente e família, enfim quando ajuda o ser cuidado. No cotidiano do trabalho de enfermagem com pacientes oncológicos há fatores gratificantes como ver o paciente recuperado, ter contato com ele, ajudálo a conhecer a doença e orientá-lo. Neste sentido, percebe-se em algumas falas das entrevistadas que ver o paciente em fase final de tratamento e com perspectivas de cura é compensador. A equipe se sente realizada profissionalmente em poder ajudar o paciente a superar uma etapa considerada difícil e complexa, até o restabelecimento de sua saúde ${ }^{(18)}$.

O sentimento de satisfação em promover o alívio do sofrimento do outro pode significar reposição de energias, busca do ponto de equilíbrio, bem-estar, cicatrização das feridas provocadas pelo sofrimento, permitindo novos enfrentamentos e melhor desempenho no seu trabalho ${ }^{(19)}$. A fala de Azul expressa satisfação ao tomar conhecimento que os pacientes se sentem acolhidos e cuidados pela equipe:

Têm pacientes aqui que gostam da gente, falam lá fora que os tratamos bem e ficamos felizes quando eles se lembram da gente. Não pelo fato de trazerem presentes, mas por sabermos que eles estão sendo bem tratados (Azul).

A equipe de enfermagem sente-se valorizada quando seu trabalho e dedicação são reconhecidos. Esse reconhecimento é manifestado pelos pacientes oncológicos por meio de gestos, palavras e mimos. 
Nesta interação, entende-se que o cuidador faz uma auto-reflexão sobre sua vida, possibilitando melhor compreensão e aceitação das situações reais que se apresentam. Isto pode ser evidenciado na fala de Azul:

Eu acho que a vivência com o paciente oncológico traz um crescimento muito grande, te dá um aspecto novo na vida. Às vezes você fica pensando que os teus problemas são grandes e o problema que tu está passando não é tão grande assim! Te ensina a aproveitar um pouco mais a vida, direcionar a tua própria vida! De repente [...] você aprende a dar valor (Azul).

O contato com o paciente oncológico proporciona modificações nas atitudes e condutas frente às dificuldades e limitações, contribuindo para que os integrantes da equipe ampliem sua visão e percebam que há pessoas vivenciando maior sofrimento e mesmo assim continuam lutando para que a vida vença.

\section{CONSIDERAÇÕES FINAIS}

Apreender as vivências de uma equipe de enfermagem relacionadas ao cuidado ao paciente oncológico constituiu-se no objetivo deste estudo. Para esses profissionais a ação de cuidar ultrapassa as ações terapêuticas, requer atendimento humanizado, criação de vínculos e compreensão do sofrimento do paciente e dos familiares.

O cuidado na enfermagem oncológica se dá numa relação comunicativa, de troca de idéias, emoções e sentimentos, ou seja, o cuidado consiste em confortar o paciente e, muitas vezes, simplesmente ouvi-lo. Está para além de administrar um quimioterápico, realizar uma seção de radioterapia, ele se estabelece numa relação de proximidade nas diversas etapas vivenciadas pelos pacientes, incluindo o processo de morrer.

No conteúdo dos depoimentos dos profissionais de enfermagem há uma riqueza de informações envolvendo conhecimento técnico-científico, relações humanas, vínculo, empatia e estabilidade emocional, para melhor conduzir tanto situações negativas como de sofrimento, de dor e perda, quanto positivas como de prazer, reconhecimento e satisfação.

Entende-se ser relevante para a equipe de enfermagem que atua em unidades oncológicas, a criação de espaço que possibilite socializar situações vivenciadas no dia-a-dia, haja vista a carga emocional implícita, a qual necessita ser melhor compreendida, compartilhada e elaborada. Este espaço contribui para o extravasamento das emoções e sentimentos, preserva a saúde dos cuidadores e melhora a qualidade da assistência aos pacientes. Lembrando que cada momento vivido no ato de cuidar em oncologia é único.

\section{REFERÊNCIAS}

1. Bettinelli LA. Cuidado solidário. Passo Fundo: Pe. Bertier; 1998.

2. Brasil. Instituto Nacional do Câncer. [acesso 2005 Nov 18]. Disponível em www.inca.gov.br/estimativa/2005.

3. Smeltzer SC, Bare BG. Brunner e Sudarth: tratado de enfermagem médico-cirúrgica. Rio de Janeiro: Guanabara Koogan; 2005.

4. Mercês NNA, Marcelino SR. Enfermagem oncológica: a representação social do câncer e o cuidado paliativo no domicílio. Blumenau: Nova Letra; 2004.

5. Black JM, Jacobs EM. Enfermagem médico-cirúrgica: uma abordagem psicofisiologica. Rio de Janeiro: Guanabara Koogan; 1996.

6. Minayo MCS, organizadora. Pesquisa social: teoria, método e criatividade. Petrópolis: Vozes; 2004.

7. Ministério da Saúde (BR). Conselho Nacional de Saúde. Diretrizes e normas regulamentadoras de pesquisa envolvendo seres humanos. Resolução $n^{\circ} 196$, de 10 de outubro de 1996. Brasília; 1996.

8. Juarez GMR. Reabilitação em oncologia: análise do conceito [tese]. Ribeirão Preto (SP): Escola de Enfermagem. Universidade de São Paulo; 2003.

9. Celich KLS. Dimensões do processo de cuidar: a visão das enfermeiras. Rio de Janeiro: EPUB; 2004.

10. Klock P, Rodrigues ACRL, Backes DS, Erdmann AL. O cuidado como produto de múltiplas interações humanas: "importando-se com o outro". Cogitare Enferm. 2007 Out/Dez; 12(4):452-9.

11. Radünz V. Cuidando e se cuidando: fortalecendo o self do cliente oncológico e o self da enfermeira [dissertação]. Florianópolis (SC): Universidade Federal de Santa Catarina; 1994.

12. Lunardi Filho WD, Sulzbach RC, Nunes AC, Lunardi 
VL. Percepções e condutas dos profissionais de enfermagem frente ao processo de morte e morrer. Texto Contexto Enferm. 2001; 10(3): 60-81.

13. Goleman D. Inteligência emocional. Rio de Janeiro: Objetiva; 1995.

14. Beck CLC. Sofrimento e esperança: vivências com familiares de pacientes internados em UTI. In: Gonzales RMB, Beck CLC, Denardin ML. Cenários de cuidado: aplicação de teorias de enfermagem. Santa Maria: Palloti; 1999.

15. Silva MJP. Percebendo o ser humano além da doença: o não verbal detectado pelo enfermeiro. Nursing. 2001; 41:14-20.

16. Moraes TM. A morte na rotina de enfermagem. In: Chiatonne HBC, Andreis M. Os limites da vida. São Paulo: Santa Casa; 1993

17. Boemer MR, Rossi LR, Nastari RR. A idéia de morte em unidade de terapia intensiva: análise de depoimentos. Rev Gaúcha Enferm. 1989; (10)2:8-14.

18. Chaves E. Stress e trabalho do enfermeiro: a influência de características individuais no ajustamento e tolerância ao turno noturno [tese]. São Paulo (SP): Instituto de Psicologia USP; 1994.

19. Beck OL. O sofrimento do trabalhador: da banalização à re-significação ética na organização da enfermagem. Florianópolis: UFSC; 2001. 